\title{
We need to include bystander first aid in trauma research
}

\author{
Håkon Kvåle Bakke ${ }^{1,2,3^{*}}$ (D) and Torben Wisborg ${ }^{2,4,5}$
}

\begin{abstract}
Background: The chain of trauma survival is a concept that originated in the area of out-of-hospital cardiac arrest (OHCA) and was adapted to the treatment of trauma. In out-of-hospital cardiac arrest research into bystander first aid has resulted in improved outcome. Whereas, in trauma research the first link of the chain of survival is almost ignored.

Methods: In OHCA, cardiopulmonary resuscitation (CPR) from bystanders has been subject of a vast amount of research, as well as measures and programs to raise the rate of bystander CPR to cardiac arrest victims. These efforts have resulted in improved survival. The research effort has been well grounded in the research community, as demonstrated by its natural inclusion in the uniform reporting template (Utstein) for the treatment of OHCA. In trauma the bystander may contribute by providing an open airway, staunch bleedings, or prevent hypothermia. In trauma however, while the chain of survival has been adopted along with it distinct links, including bystander first aid, the consensus-based uniform reporting template for trauma (the Utstein template) does not include the bystander first aid efforts. There is extremely little research on what first aid measures bystanders provide to trauma victims, and on what impact such measures have on outcome. An important step to improve research on bystander first aid in trauma would be to include this as part of the uniform reporting template for trauma

Conclusion: The lack of research on bystander first aid makes the first link in the trauma chain of survival the weakest link. We, the trauma research community, should either improve our research and knowledge in this area, or remove the link from the chain of survival
\end{abstract}

\section{Background}

The chain of trauma survival is a concept that originated in the area of out-of-hospital cardiac arrest (OHCA) and adapted to the treatment of trauma [1, 2], (Fig. 1). It is boldly stated that each link in the chain is important for the survival of the trauma patient. Allegedly the chain is no stronger than its weakest link. This strong rhetoric, though fetching, belies the fact that we in trauma ignore the first link except in schematic presentations as Fig. 1.

In OHCA, cardiopulmonary resuscitation (CPR) from bystanders has been subject of a vast amount of research, as well as measures and programs to raise the rate of bystander CPR to cardiac arrest victims [3-5]. It

\footnotetext{
* Correspondence: hakonkvalebakke@gmail.com

${ }^{1}$ Mo i Rana Hospital, Helgeland Hospital Trust, Mo i Rana, Norway

${ }^{2}$ Anaesthesia and Critical Care Research Group, Faculty of Health Sciences,

IKM, University of Tromsø, Tromsø, Norway

Full list of author information is available at the end of the article
}

is established that bystander CPR improves survival, and approximately how much $[6,7]$. We have an overview of bystander CPR-rates and that they vary geographically $[8,9]$. In addition to research into how CPR best can be carried out to improve patients survival [10] there is considerable attention on how best to teach CPR $[11,12]$ and if training has any effect $[13,14]$, as well as how dispatch instruction can improve quality and rate of bystander CPR $[15,16]$. The research effort has been well grounded in the research community, as demonstrated by its natural inclusion in the uniform reporting template (Utstein) for the treatment of OHCA [17]. These investigative efforts have proven fruitful on several occasions, improving CPR-rate considerably, and even survival $[9,18]$.

In trauma bystander CPR has a more limited role, as traumatic cardiac arrest has a different aetiology and prognosis. However there are several other measures the 


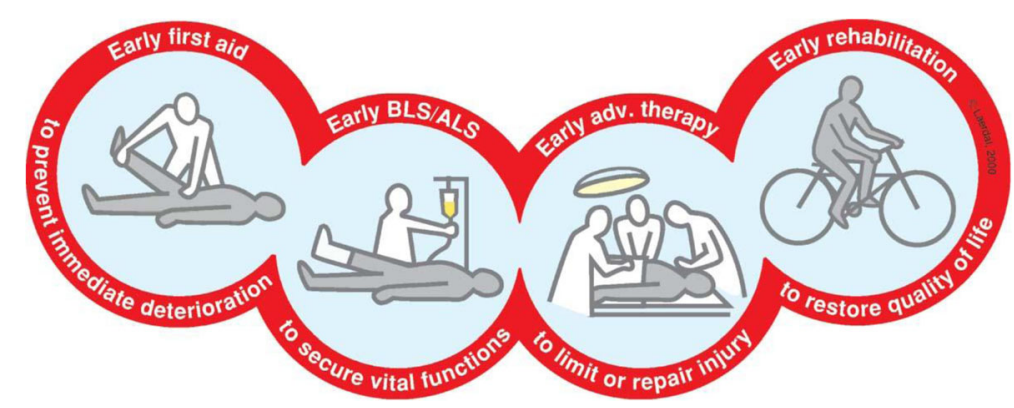

Fig. 1 The trauma chain of survival. Reproduced with permission from Laerdal Medical, Stavanger, Norway

bystander may provide, such as airway manoeuvres, compression of visible bleeding, and the prevention of hypothermia [19]. In trauma however, while the chain of survival has been adopted along with it distinct links, including bystander first aid, the consensus-based uniform reporting template (the Utstein template) does not bother to include the bystander first aid efforts [20]. There may be several reasons for this, but there is no attempt to explain the omission, so we are left to speculate. The current edition of the Utstein template has been criticised for omitting those trauma victims that die prehospitally, leading to inconsistency of methodology and terminology in the reporting on prehospital trauma deaths [21]. We fear that the lack of emphasis on prehospital care in the Utstein template is contributory to the lack of research on bystander first aid in trauma.

Because unfortunately, the omission of bystander first aid is not restricted to the reporting template for trauma. In 2012 we did a review on bystanders first aid in trauma and found a mere 11 studies world-wide on the subject, most were questionnaire-based surveys [19]. Little has changed since then, and a quick search in the PubMed database reveals that the only study that have investigated the role of bystander first aid is a study we ourselves conducted [22]. Likewise, in our work with dispatch assisted first aid we again found that this topic was well-covered for OHCA, but not for trauma. If we really do believe that the first aid from bystanders constitute an important link in the chain of trauma survival, then we should also conduct research concerning that link. In fact, the omission of this link from the Utstein template might have led researchers to the false belief that the question was already solved.

It is possible that bystander first aid in trauma has little effect on survival, that it is already optimised, and it is possible that our efforts on improving trauma survival is best spent elsewhere. But the fact of the matter is that we do not know, and we cannot know, until we have investigated. Reporting on bystander first aid should be included in the next Utstein template revision, and research should be encouraged and demanded. It may be that not all research will or can follow the template reporting recommendation. However, it will signal that research into first aid from bystanders actually is of interest, and we believe it is an important step to improving research in this field.

\section{Conclusion}

The lack of research on bystander first aid makes the first link in the trauma chain of survival the weakest link. We, the trauma research community, should improve our research and knowledge in this area. Else we might as well remove this link from the chain entirely, not because we know whether it is unimportant, but because we have decided that we do not care.

\section{Abbreviations}

CPR: Cardiopulmonary resuscitation; OHCA: Out-of-hospital cardiac arrest

\section{Acknowledgements}

Not applicable.

\section{Funding}

Not applicable.

\section{Availability of data and materials \\ Not applicable.}

\section{Authors' contributions}

HKB and TW drafted the manuscript. Both authors read and approved the final manuscript.

\section{Competing interests}

Bakke is a previous volunteer for the Norwegian Red Cross Troms $\varnothing$ who receives income from first-aid courses. He has worked as first-aid instructor for Red Cross Tromsø. The authors declare that they have no competing interests.

\section{Consent for publication \\ Not applicable.}

\section{Ethics approval and consent to participate}

Not applicable.

\section{Author details}

${ }^{1}$ Mo i Rana Hospital, Helgeland Hospital Trust, Mo i Rana, Norway. ${ }^{2}$ Anaesthesia and Critical Care Research Group, Faculty of Health Sciences, IKM, University of Tromsø, Tromsø, Norway. ${ }^{3}$ Department of Anaesthesiology and Intensive Care, University Hospital of North Norway, Tromsø, Norway. ${ }^{4}$ Department of Anaesthesiology and Intensive Care, Hammerfest Hospital, Finnmark Health Trust, Hammerfest, Norway. ${ }^{5}$ Norwegian National Advisory 
Unit on Trauma, Division of Emergencies and Critical Care, Oslo University Hospital, Oslo, Norway.

Received: 21 December 2016 Accepted: 27 February 2017 Published online: 23 March 2017

\section{References}

1. Deakin CD, Søreide E. Pre-hospital trauma care. Curr Opin Anesthesiol. 2001;14:191.

2. Søreide K. Strengthening the trauma chain of survival. Br J Surg. 2011;99:1-3.

3. Berdowski J, Berg RA, Tijssen JGP, Koster RW. Global incidences of outof-hospital cardiac arrest and survival rates: Systematic review of 67 prospective studies. Resuscitation. 2010;81:1479-87.

4. Olasveengen TM, Vik E, Kuzovlev A, Sunde K. Effect of implementation of new resuscitation guidelines on quality of cardiopulmonary resuscitation and survival. Resuscitation. 2009;80:407-11.

5. Wissenberg M, Lippert FK, Folke F, Weeke P, Hansen CM, Christensen EF, et al. Association of National Initiatives to Improve Cardiac Arrest Management With Rates of Bystander Intervention and Patient Survival After Out-of-Hospital Cardiac Arrest. JAMA. 2013;310:1377-8.

6. Sasson C, Rogers MAM, Dahl J, Kellermann AL. Predictors of Survival From Out-of-Hospital Cardiac Arrest: A Systematic Review and Meta-Analysis. Circ Cardiovasc Qual Outcomes. 2010;3:63-81.

7. Holmberg M, Holmberg S, Herlitz J. Effect of bystander cardiopulmonary resuscitation in out-of-hospital cardiac arrest patients in Sweden. Resuscitation. 2000:47:59-70.

8. Nichol G, Thomas E, Callaway CW, Hedges J, Powell JL, Aufderheide TP, et al. Regional variation in out-of-hospital cardiac arrest incidence and outcome. JAMA. 2008;300:1423-31.

9. Bray JE, Deasy C, Walsh J, Bacon A, Currell A, Smith K. Changing EMS dispatcher CPR instructions to 400 compressions before mouth-to-mouth improved bystander CPR rates. Resuscitation. European Resuscitation Council, American Heart Association, Inc., and International Liaison Committee on Resuscitation. 2011;82:1393-8.

10. Hüpfl M, Selig HF, Nagele P. Chest-compression-only versus standard cardiopulmonary resuscitation: a meta-analysis. Lancet. 2010;376:1552-7.

11. Bohn A, Van Aken H, Lukas RP, Weber T, Breckwoldt J. Schoolchildren as lifesavers in Europe - training in cardiopulmonary resuscitation for children. Best Pract Res Clin Anaesthesiol. 2013;27:387-96.

12. Bollig G, Wahl HA, Svendsen MV. Primary school children are able to perform basic life-saving first aid measures. Resuscitation. 2009;80:689-92.

13. Tanigawa K, Iwami T, Nishiyama C, Nonogi H, Kawamura T. Are trained individuals more likely to perform bystander CPR? An observational study. Resuscitation. 2011:82:523-8.

14. Swor R, Khan I, Domeier R, Honeycutt L, Chu K, Compton S. CPR Training and CPR Performance: Do CPR-trained Bystanders Perform CPR? Acad Emerg Med. 2006;13:596-601.

15. Vaillancourt C, Charette ML, Bohm K, Dunford J, Castrén M. In out-ofhospital cardiac arrest patients, does the description of any specific symptoms to the emergency medical dispatcher improve the accuracy of the diagnosis of cardiac arrest: A systematic review of the literature. Resuscitation. 2011;82:1483-9.

16. Hardeland C, Olasveengen TM, Lawrence R, Garrison D, Lorem T, Farstad G, et al. Comparison of Medical Priority Dispatch (MPD) and Criteria Based Dispatch (CBD) relating to cardiac arrest calls. Resuscitation. 2014:85:612-6.

17. Cummins RO, Chamberlain DA, Abramson NS, Allen M, Baskett PJ, Becker $L$, et al. Recommended guidelines for uniform reporting of data from out-of-hospital cardiac arrest: the Utstein Style. A statement forhealth professionals from a task force of the American Heart Association, the European Resuscitation Council, the Heart and Stroke Foundation of Canada, and the Australian Resuscitation Council. Circulation. 1991:84:960-75.

18. Lindner TW, Søreide E, Nilsen OB, Torunn MW, Lossius HM. Good outcome in every fourth resuscitation attempt is achievable-An Utstein template report from the Stavanger region. Resuscitation. 2011;82:1508-13.

19. Tannvik TD, Bakke HK, Wisborg T. A systematic literature review on first aid provided by laypeople to trauma victims. Acta Anaesthesiol Scand. 2012;56:1222-7.

20. Ringdal KG, Coats TJ, Lefering R, Di Bartolomeo S, Steen PA, Røise O, et al. The Utstein template for uniform reporting of data following major trauma: a joint revision by SCANTEM, TARN, DGU-TR and RITG. Scandinavian Journal of Trauma, Resuscitation and. Emerg Med. 2008;16:7.
21. Oliver GJ, Walter DP. A Call for Consensus on Methodology and Terminology to Improve Comparability in the Study of Preventable Prehospital Trauma Deaths: A Systematic Literature Review. Acad Emerg Med. 2016:23:503-10.

22. Bakke HK, Steinvik T, Eidissen S-I, Gilbert M, Wisborg T. Bystander first aid in trauma - prevalence and quality: a prospective observational study. Acta Anaesthesiol Scand. 2015;59:1187-93.

\section{Submit your next manuscript to BioMed Central and we will help you at every step:}

- We accept pre-submission inquiries

- Our selector tool helps you to find the most relevant journal

- We provide round the clock customer support

- Convenient online submission

- Thorough peer review

- Inclusion in PubMed and all major indexing services

- Maximum visibility for your research

Submit your manuscript at www.biomedcentral.com/submit
Biomed Central 